\title{
Examining the role of subjective and objective burden in carer health-related quality of life: the case of colorectal cancer
}

\author{
Paul Hanly • Rebecca Maguire • Philip Hyland • Linda Sharp
}

Received: 23 August 2014 / Accepted: 30 November 2014 / Published online: 12 December 2014

(C) Springer-Verlag Berlin Heidelberg 2014

\begin{abstract}
Purpose Our aim was to investigate associations between the subjective burden of care and health-related quality of life (both physical and mental) within colorectal cancer patient carers in Ireland, with supplementary analysis of carer objective factors.

Methods Two hundred twenty-eight colorectal cancer informal carers were sent a postal questionnaire between August 2010 and March 2011 which included the Caregiver Reaction Assessment (CRA) and the SF-12v2. Multiple regression analysis assessed whether five CRA domains (family support, finances, schedule, health and esteem) predicted carer mental or physical health. Between-group comparisons investigated differences in these domains across objective factors.

Results One hundred fifty-three carers ( $82 \%$ female) completed the questionnaire (response rate $=68 \%$ ). Carers' mean physical component summary (PCS) was $48.56(\mathrm{SD}=10.38)$ and mean mental component summary (MCS) was 49.22 $(\mathrm{SD}=9.7)$. Five CRA factors explained $30 \%$ of variance in the PCS score and $28 \%$ of variance in the MCS score. Health burden $(\beta=-.76, p<.001)$ and schedule burden $(\beta=.28$, $p=.01)$ were significant predictors of PCS. MCS was significantly predicated by financial burden $(\beta=-.24, p=.01)$ and esteem $(\beta=-.18, p=.03)$. Younger carers, spouses, those with a comorbid condition and those with no income change had significantly lower PCS. There were no statistically significant group differences for carer mental health.

Conclusions Our results demonstrate the need to recognise the distinctive aspects of the impact of caring (i.e., physical
\end{abstract}

P. Hanly $(\varangle) \cdot$ R. Maguire $\cdot$ P. Hyland

National College of Ireland, Mayor Street, Dublin 1, Ireland

e-mail: paul.hanly@ncirl.ie

\section{Sharp}

National Cancer Registry Ireland, Cork Airport Business Park, Kinsale Road, Cork, Ireland and mental) on carers and that different domains of subjective carer burden and objective factors impact differently on each of these. This has important implications for those delivering support to carers over the course of the survivorship continuum.

Keywords Quality of life - Burden · Colorectal cancer . Carers · Ireland

\section{Introduction}

Colorectal cancer is the second most common cancer in Europe with an estimated 447,000 new cases diagnosed in 2012 [1]. In Ireland, in common with other European countries, the number of new male and female colorectal cancer cases has increased steadily over the last 20 years and survival rates have also risen [2,3]. Consequently, the number of people living with colorectal cancer is increasing [4]. Survivors are living longer with their disease, and, like other cancers, colorectal cancer is increasingly recognised as a chronic condition. This, and other trends - notably a movement towards increasing delivery of care in an outpatient setting - means that informal carers of cancer survivors have an increasingly important role in providing assistance and supportive care [5-9].

While caregiving for cancer patients can have positive effects [10], it can also impose a considerable burden as carers integrate complex support tasks, both emotional and physical, into their lives [9]. Patients diagnosed and treated for colorectal cancer may experience severe pain, weight loss, nausea and fatigue [9, 11-13]. A large proportion also has either a temporary or a permanent stoma [14]. Their carers therefore face challenges in supporting patients in the early stages of diagnosis and treatment and in providing ongoing support and care $[15,16]$. Ongoing domestic-related caregiving tasks, for 
example, can include extra housework, support with instrumental activities of daily living and cancer-specific care [17].

There is now a growing recognition that the needs of caregivers should be acknowledged across the survivorship continuum [18]. Kim et al. [19] recently examined these needs which include cognitive/informational, communication, daily activities, emotional, financial/legal, medical, social/ relationship and spiritual. Stenberg et al. [20] have reviewed the effects of caring for a patient with cancer. The impacts of caring on the caregiver included physical problems, such as sleep disturbance, fatigue and pain; social problems, including feelings of isolation and financial strain; and emotional problems including feelings of fear, uncertainty and hopelessness. While a reasonably extensive literature exists on the effects of caring for cancer patients, key predictors of carer health and well-being are under-researched and require identification so that provisions for carer support can be more effectively delivered $[6,21]$.

The literature to date has identified a number of predictors of health-related quality of life (HRQoL) in carers of cancer patients including the following: patient/treatment-related factors [22], the patient's physical care needs [23], the patient's QoL [24], carer socio-demographic factors (employment status, income level, education [25]) and caregiving specific factors (e.g. time in caregiving role [26]). While a limited literature base exists examining the effect of objective burden factors (defined here as the time involved in caring and the out-of-pocket costs incurred due to caring activities), the subjective carer burden (i.e. the impact that carers perceive caring to have on different aspects of their lives) has rarely been investigated as a predictor of carer HRQoL. In addition, the majority of studies have concentrated on the predictors of psychological, as opposed to physical, health [27], and only one appears to have focused on the HRQoL of colorectal cancer patient carers [14].

The primary aim of our study was therefore to investigate associations between the subjective burden of care and HRQoL (both physical and mental) within colorectal cancer patient carers. Furthermore, in supplementary analysis, we aimed to examine differences between carer physical and mental health and objective carer factors (including objective burden, socio-demographic characteristics, carer relationship to patient and carer health).

\section{Materials and methods}

Study design and sample

This study has been approved by the appropriate ethics committees, and all participants signed the informed consent form. We initially identified colorectal survivors in Ireland from the National Cancer Registry Ireland. Survivors were between
6 months and 2.5 years post diagnosis. Four hundred ninetyfive survivors took part in the survey which represented a response rate of $39 \%$. As part of this survey, respondents were asked whether a family member, friend or another person had been helping in taking care of them since their diagnosis and, if so, to provide contact details; the named individual was designated an informal carer. Two hundred twenty-eight survivors indicated that they had a carer and provided contact details. A carer postal survey was undertaken August 2010 March 2011 when survivors were between a year and 3 years post diagnosis.

\section{Questionnaire and instruments}

The carer questionnaire was developed from a literature review and in-depth interviews with colorectal cancer survivors and their family members [28]. It included questions on carer socio-demographic and economic characteristics (including age, gender, marital status and employment status), the carer's relationship to the colorectal cancer survivor, whether the carer lived with the care recipient, whether the carer was the sole caregiver and whether they had comorbidities or had experienced any change in income since commencing caregiving.

Carer subjective burden was assessed by the Caregiver Reaction Assessment (CRA) scale [29] which has been shown to be reliable and valid [30]. The CRA includes 24 items which aggregate to four "negative" subscales (impact of caregiving on schedule, finances and health, and lack of family support) and one "positive" subscale (impact of caregiving on carer esteem). For each item, carers were asked to rate the current impact of caring on a 5-point Likert scale ranging from 1 (strongly disagree) to 5 (strongly agree). A total score was computed for each subscale with a possible range of 1 (best) to 5 (worst). The self-esteem positive subscale was negatively scored so that interpretation conformed to the negative subscales. A higher score equates to a greater burden on all subscales.

A subsection of the questionnaire assessed carer objective burden, which was operationalised as the amount of time spent caring for the colorectal cancer patient and the out-ofpocket costs incurred while caring. Specifically, carers were asked to indicate in the 30 days prior to questionnaire completion (i) additional time spent per week on domestic-related caring activities (housework, activities of daily living (ADL), instrumental activities of daily living (IADL) and cancerspecific care [31]) and (ii) additional out-of-pocket (OOP) costs per week incurred due to caring (including spending on medicines, household items and cancer-related items such as home help and stomas [17]). The questions on time spent caring and associated categories were based on those developed by van den Berg and Spauwen [31]; spending categories were based on those developed by Hanly et al. [17]. 
Informal carer physical and mental health was measured using the 12-Item Short Form Health Survey (SF-12v2), a validated multidimensional generic measure of HRQoL [32] consisting of eight health domain scales: physical functioning (two items), role-physical functioning (two items), bodily pain (one item), general heath (one item), vitality (one item), social functioning (one item), role-emotional functioning (two items) and mental health (two items). A physical component summary (PCS) score (which contains all eight SF12v2 health domain scales but is correlated most highly with physical functioning, role-physical functioning, bodily pain and general health) and a mental component summary (MCS) score (containing all eight health domain scales but correlated most highly with mental health, role-emotional functioning, social functioning and vitality) were calculated [32]. Specifically, PCS and MCS were computed by multiplying each health domain scale score by PCS- or MCS-specific coefficients which are derived for the SF36 from the 1990 US general population. There are no Irish SF12v2 norms, but previous research indicated that there were no significant differences between normative values for the SF-36 (scores for which are highly correlated with SF12 scores) in the Irish and US populations [33]; hence, we standardised to the SF12 US population norms to provide PCS and MCS scores in the range $0-100($ mean $=50, S D=10)$. Lower PCS or MCS indicate more limitations in functioning. Missing SF-12v2 data were dealt with in accordance with scoring manuals [32].

\section{Statistical analysis}

Standard multiple regression analysis was performed to investigate the ability of the five CRA factors to predict PCS and MCS. In this part of the analysis, variables were considered statistically significant at the $5 \%$ level. Preliminary analyses were conducted to ensure no violation of the assumptions of normality, linearity and homoscedasticity. All measures were normally distributed with the exception of the objective burden scores. Due to the variable nature of this data, we recoded it into three categories. Additionally, the correlations amongst the predictor variables were assessed to ensure multicollinearity was not an issue. Subjects with missing data for variables included in the analyses were excluded on a pairwise basis.

Independent sample $t$ tests and one-way between-group analysis of variance (ANOVA) were conducted to investigate differences in PCS and MCS on a range of objective factors including objective burden (carer incurred time and OOP costs), socio-demographic characteristics, carer relationship to patient and carer health for our supplementary analysis. In this part of the analysis, Bonferroni corrections were applied to accommodate multiple testing; the notional alpha was 0.005 (i.e. $0.05 / 10$ ). Effect sizes for group differences were calculated using partial eta-squared values $\left(\eta^{2}\right)$. While
Cohen's $d$ is generally reported as the measure of effect size for $t$ tests, eta-squared results can just as reliably be reported for $t$ test analysis as well as ANOVA [34]. Interpretations of the eta-squared effect size are consistent for $t$ tests and ANOVA [34, 35]. We therefore decided to use one measure of effect size for all analyses to avoid potential confusion. According to Cohen [36], $\eta^{2}$ values of 0.01-0.05 suggest a small effect between mean scores, values of $0.06-0.13$ indicate a medium effect and values of $\geq 0.14$ indicate a large effect.

\section{Results}

Carer characteristics

Carer characteristics are summarised in Table 1. A total of 153 carers (28 males and 125 females) completed the questionnaire (response rate $=68 \%$ ) and carer age ranged from 21 to $83($ mean $=58.3 ; \mathrm{SD}=13.0)$.

Carer subjective burden, objective burden, physical QoL and mental QoL: descriptive results

Descriptive statistics for the five CRA factors, two carer objective burden factors, and PCS and MCS are provided in Table 2. The most negatively affected CRA domain was disrupted schedule (mean $=3.0, \mathrm{SD}=1.0$ ), followed by financial problems $($ mean $=2.4, \mathrm{SD}=0.9)$, health problems $($ mean $=$ $2.3, \mathrm{SD}=0.7$ ) and lack of family support (mean=2.0, $\mathrm{SD}=$ 0.8 ). Carers' scores indicated a low level of esteem burden (mean=1.7, $\mathrm{SD}=0.5)$. Two in three carers $(68 \%)$ reported dedicating some time to caregiving tasks in the previous 30 days, and the mean time involved was $20 \mathrm{~h}$ per week. Approximately half (51\%) of all carers incurred some caringrelated OOP costs. Carers' mean PCS was 48.56 ( $\mathrm{SD}=10.38$; median=51.61; range 17-65) and mean MCS was 49.22 $(\mathrm{SD}=9.70$; median=51.34; range 17-68). Neither value was significantly different from population norms.

Associations between subjective burden and carer PCS and MCS

Table 3 summarises the results of subjective burden factors as predictors of carer PCS and MCS. The five CRA factors explained $29.5 \%$ of variance $\left(\operatorname{adj} R^{2}=0.27\right)$ in PCS $(p<.001)$. Two of the five factors significantly contributed to the prediction of PCS; health burden $(\beta=-0.76, p<.001)$ and schedule burden $(\beta=.28, p<.01)$. Higher levels of health burden were strongly associated with lower levels of PCS, while higher levels of schedule burden were more weakly associated with higher PCS. 
Table 1 Carer characteristics

\begin{tabular}{|c|c|c|}
\hline Carer characteristic & Number & Percent ${ }^{\mathrm{a}}$ \\
\hline \multicolumn{3}{|l|}{ Age } \\
\hline$\leq 61$ & 76 & 50.3 \\
\hline$>61$ & 75 & 49.7 \\
\hline \multicolumn{3}{|l|}{ Gender } \\
\hline Male & 28 & 18.2 \\
\hline Female & 125 & 81.2 \\
\hline \multicolumn{3}{|l|}{ Employment status } \\
\hline Employed & 68 & 45.9 \\
\hline Looking after home & 38 & 25.7 \\
\hline Retired & 33 & 22.3 \\
\hline Other & 8 & 6.1 \\
\hline \multicolumn{3}{|l|}{ Relationship to patient } \\
\hline Spouse/cohabiting & 111 & 73 \\
\hline Son/daughter & 29 & 19.1 \\
\hline Parent & 8 & 5.3 \\
\hline Other & 4 & 2.6 \\
\hline \multicolumn{3}{|l|}{ Sole carer } \\
\hline Yes & 107 & 69.5 \\
\hline No & 42 & 27.3 \\
\hline \multicolumn{3}{|l|}{ Children } \\
\hline Carer has children & 127 & 83.0 \\
\hline Carer does not have children & 26 & 17.0 \\
\hline \multicolumn{3}{|l|}{ Medical condition (comorbidity) } \\
\hline Yes & 42 & 27.3 \\
\hline No & 103 & 66.9 \\
\hline \multicolumn{3}{|l|}{ Income change since diagnosis } \\
\hline Increased/stayed the same & 96 & 62.3 \\
\hline Decreased & 48 & 31.2 \\
\hline
\end{tabular}

${ }^{a}$ These figures refer to the percentage of the sample who answered the question
The five CRA factors explained $28.3 \%$ of variance $\left(\operatorname{adj} R^{2}=.26\right)$ in MCS $(p<.001)$. Two of the five variables significantly contributed to the explanation of MCS; financial burden was the strongest predictor $(\beta=.24, p<.01)$, followed by esteem $(\beta=.18, p<.05)$. Higher levels of both financial burden and esteem were weakly associated with lower MCS.

Group differences in carer PCS by objective factors

Table 4 summarises group differences for PCS by objective burden and other objective factors. No statistically significant effects were observed for OOP costs $(p=.62)$ or time dedicated to caregiving activities $(p=.66)$ on PCS. Carers with a comorbid condition $\left(p=.001 ; \eta^{2}=.22\right)$ and those aged over 61 years of age, compared to those aged 61 or under $(p<.001$, $\eta^{2}=.15$ ), reported significantly lower PCS. PCS also varied according to relationship status, with spousal carers reporting significantly lower PCS than non-spousal carers $(p=.001$; $\eta^{2}=.14$ ). In addition, carers who experienced no change in income had a lower PCS than those who experienced a decrease in income $\left(p=.003 ; \eta^{2}=.06\right)$. While no statistically significant effect was observed in PCS by employment status $(p=.009)$, retired individuals had lower PCS compared to those in paid employment $\left(\eta^{2}=.09\right)$.

\section{Group differences in carer MCS by objective factors}

Table 5 summarises group differences for MCS. No statistically significant group differences emerged for objective carer burden factors or for any socio-demographic and carer factors. Although not statistically significant, evidence did exist for possible differences in MCS by financial variables. Those whose income decreased reported weak to moderately lower MCS compared to those whose income remained unchanged $\left(p=.19 ; \eta^{2}=.04\right)$, while a moderate difference was observed in
Table 2 Descriptive statistics for key carer PCS and MCS and subjective and objective carer burden

\begin{tabular}{|c|c|c|c|c|}
\hline Measure & Number & Mean & $\mathrm{SD}$ & Range \\
\hline \multicolumn{5}{|l|}{ Health-related QoL (SF12v2) } \\
\hline Physical component summary (PCS) & 145 & 48.4 & 10.5 & $17-65$ \\
\hline Mental component summary (MCS) & 145 & 49.3 & 9.7 & $17-68$ \\
\hline \multicolumn{5}{|l|}{ Subjective burden (CRA) } \\
\hline Carer esteem & 149 & 1.7 & 0.5 & $1-3$ \\
\hline Disrupted schedule & 150 & 3.0 & 1.0 & $1-5$ \\
\hline Lack of family support & 150 & 2.0 & 0.8 & $1-4$ \\
\hline Financial problems & 150 & 2.4 & 1.0 & $1-5$ \\
\hline Health problems & 150 & 2.3 & 0.7 & $1-4$ \\
\hline \multicolumn{5}{|l|}{ Objective burden } \\
\hline Caring-related OOP costs ( $€$ per week) & 146 & 58.6 & 135.4 & $0-1020$ \\
\hline Time spent on caregiving (hours per week) & 139 & 20.2 & 28.0 & $0-135$ \\
\hline
\end{tabular}


Table 3 Multiple regression model summarising carer subjective burden domains as predictors of carer PCS and MCS

\begin{tabular}{|c|c|c|c|c|c|c|c|c|}
\hline Variables & $R$ & $R^{2}$ & $\operatorname{Adj} R^{2}$ & $\beta$ & $B$ & SE & CI $95 \%$ (B) & $p$ value \\
\hline \multicolumn{9}{|l|}{ PCS } \\
\hline Model & .543 & $.295^{* * *}$ & .270 & & & & & \\
\hline Family support & & & & .17 & 2.26 & 1.21 & $-.14 / 4.66$ & .065 \\
\hline Finances & & & & .13 & 1.66 & 1.05 & $-.41 / 3.73$ & .115 \\
\hline Schedule & & & & .28 & 3.01 & 1.19 & $.66 / 5.36$ & .012 \\
\hline Health & & & & -.76 & -10.91 & 1.48 & $-13.83 /-7.98$ & $<.001$ \\
\hline Esteem & & & & -.08 & -1.73 & 1.65 & $-1.53 / 4.98$ & .296 \\
\hline \multicolumn{9}{|l|}{ MCS } \\
\hline Model & .532 & $.283^{* * *}$ & .257 & & & & & \\
\hline Family support & & & & -.16 & -1.92 & 1.13 & $-4.16 / .31$ & .091 \\
\hline Finances & & & & -.24 & -2.80 & .97 & $-4.73 /-.88$ & .005 \\
\hline Schedule & & & & -.13 & -1.29 & 1.11 & $-3.48 / .90$ & .244 \\
\hline Health & & & & -.16 & -2.17 & 1.38 & $-4.89 / .55$ & .117 \\
\hline Esteem & & & & -.18 & -3.39 & 1.53 & $-.36 /-6.42$ & .028 \\
\hline
\end{tabular}

Note PCS and MCS models, $N=143$; statistical significance $* * * p<.001$

Table 4 Group differences for carer PCS: objective factors

\begin{tabular}{|c|c|c|c|c|c|c|c|}
\hline Carer variables & Group & Number & Mean & SD & $t / F$ & $p$ value & $\eta^{2}$ \\
\hline \multirow[t]{2}{*}{ Age } & $\leq 61$ & 78 & 52.12 & 9.00 & 5.08 & $<.001^{*}$ & .15 \\
\hline & $>61$ & 65 & 43.71 & 10.54 & & & \\
\hline \multirow[t]{2}{*}{ Gender } & Male & 26 & 49.56 & 9.45 & .54 & .591 & .00 \\
\hline & Female & 117 & 48.34 & 10.60 & & & \\
\hline \multirow[t]{4}{*}{ Employment status } & Paid & 66 & 51.70 & 8.46 & 4.05 & .009 & .09 \\
\hline & Homemaker & 34 & 46.28 & 11.61 & & & \\
\hline & Retired & 30 & 44.98 & 10.94 & & & \\
\hline & Other & 8 & 46.69 & 12.48 & & & \\
\hline \multirow[t]{2}{*}{ Relationship to patient } & Spouse & 103 & 46.52 & 10.73 & -4.78 & $<.001^{*}$ & .14 \\
\hline & Other & 39 & 54.00 & 7.19 & & & \\
\hline \multirow[t]{2}{*}{ Sole carer } & No & 98 & 47.66 & 10.39 & -1.72 & .089 & .02 \\
\hline & Yes & 41 & 50.93 & 9.84 & & & \\
\hline \multirow[t]{2}{*}{ Children } & Yes & 117 & 47.73 & 10.35 & 2.07 & .040 & .03 \\
\hline & No & 26 & 52.33 & 9.86 & & & \\
\hline \multirow[t]{2}{*}{ Medical condition (comorbidity) } & Yes & 39 & 39.77 & 11.67 & 6.11 & $<.001^{*}$ & .22 \\
\hline & No & 97 & 52.10 & 7.51 & & & \\
\hline \multirow[t]{2}{*}{ Income change } & No Change & 90 & 47.07 & 10.67 & -3.03 & $.003 *$ & .06 \\
\hline & Decrease & 46 & 52.11 & 8.32 & & & \\
\hline \multirow[t]{3}{*}{ Caring-related OOP costs } & No extra costs & 65 & 49.55 & 9.04 & .48 & .623 & .01 \\
\hline & $€ 1-€ 43$ extra & 36 & 48.51 & 10.35 & & & \\
\hline & $€ 44+$ & 36 & 47.50 & 12.13 & & & \\
\hline \multirow[t]{3}{*}{ Time spent on caregiving (h) } & 0 & 41 & 47.65 & 11.72 & .41 & .663 & .01 \\
\hline & $1-24$ & 43 & 49.67 & 8.14 & & & \\
\hline & $25+$ & 46 & 48.45 & 10.77 & & & \\
\hline
\end{tabular}

Statistical significance $* p<.005, \eta^{2}=$ partial eta-squared effect size 
Table 5 Group differences for carer MCS: objective factors

\begin{tabular}{|c|c|c|c|c|c|c|c|}
\hline Carer variable & Group & Number & Mean & SD & $t / F$ & $p$ value & $\eta^{2}$ \\
\hline \multirow[t]{2}{*}{ Age } & $\leq 61$ & 78 & 47.71 & 10.60 & -2.21 & .029 & .03 \\
\hline & $>61$ & 65 & 51.15 & 8.08 & & & \\
\hline \multirow[t]{2}{*}{ Gender } & Male & 26 & 48.91 & 9.92 & -.18 & .859 & .00 \\
\hline & Female & 117 & 49.29 & 9.72 & & & \\
\hline \multirow[t]{4}{*}{ Employment status } & Paid & 66 & 48.07 & 10.82 & 1.32 & .272 & .03 \\
\hline & Homemaker & 34 & 50.50 & 9.55 & & & \\
\hline & Retired & 30 & 51.27 & 7.52 & & & \\
\hline & Other & 8 & 45.59 & 8.29 & & & \\
\hline \multirow[t]{2}{*}{ Relationship to patient } & Spouse & 103 & 49.97 & 9.02 & 1.59 & .11 & .02 \\
\hline & Other & 39 & 47.08 & 11.28 & & & \\
\hline \multirow[t]{2}{*}{ Sole carer } & Yes & 98 & 49.99 & 9.88 & 1.35 & .178 & .01 \\
\hline & No & 41 & 47.53 & 9.55 & & & \\
\hline \multirow[t]{2}{*}{ Children } & Yes & 117 & 49.07 & 9.68 & .39 & .696 & .00 \\
\hline & No & 26 & 49.90 & 10.08 & & & \\
\hline \multirow[t]{2}{*}{ Medical condition (comorbidity) } & Yes & 39 & 48.13 & 9.49 & 1.08 & .284 & .01 \\
\hline & No & 97 & 50.12 & 9.84 & & & \\
\hline \multirow[t]{2}{*}{ Income change } & No Change & 90 & 47.07 & 10.67 & 2.37 & .019 & .04 \\
\hline & Decrease & 46 & 52.11 & 8.32 & & & \\
\hline \multirow[t]{3}{*}{ Caring-related OOP costs } & No extra costs & 65 & 51.77 & 8.18 & 4.24 & .016 & .06 \\
\hline & $€ 1-€ 43$ extra & 36 & 47.40 & 9.56 & & & \\
\hline & $€ 44+$ & 36 & 46.59 & 11.63 & & & \\
\hline \multirow[t]{3}{*}{ Time spent on caregiving (h) } & 0 & 41 & 50.25 & 7.19 & .37 & .694 & .00 \\
\hline & $1-24$ & 43 & 49.91 & 8.89 & & & \\
\hline & $25+$ & 46 & 48.62 & 11.56 & & & \\
\hline
\end{tabular}

$\eta^{2}=$ partial eta-squared effect size

the mean MCS between those carers who reported no extra caring-related OOP costs and those who did $\left(p=.02, \eta^{2}=.06\right)$.

\section{Discussion}

Our study has revealed the considerable impact that both subjective and objective carer burden has on HRQoL of carers of colorectal cancer patients. In particular, carer subjective burden was important in explaining both carer physical and mental HRQoL, while socio-demographic and health factors were only significant in predicting carer physical HRQoL.

Subjective burden as a predictor of carer physical and mental health

Bevans and Sternberg [37] suggest that degradations in physical health amongst cancer carers may be primarily attributed to perceived carer burden. However, in our model, only two of the five CRA subscales - impact on health and impact on schedule - were significant predictors of carer physical health.
While the negative relationship between health burden and physical health seems entirely intuitive, the positive relationship between higher schedule impact and better physical health is intriguing. We might speculate that those reporting a higher schedule burden may have additional commitments (such as work or family commitments) that could further exacerbate the perceived schedule burden of caring, but which would require higher physical health to begin with. For example, those in employment would be expected to be more physically healthy (and this is observed in our sample of carers), yet this employment would put greater constraints on the available time to dedicate to caring and hence might lead the individual to report a higher subjective schedule burden.

A higher subjective financial burden significantly predicted mental health, and this was also reflected in our investigation of differences in MCS by objective factors which found that, although not statistically significant, the largest effect size on carer MCS was accounted for by OOP costs $\left(\eta^{2}=0.06\right)$. The economic and financial effects of caring have begun to be more widely recognised, and distinct aspects of the burden areas have started to be distinguished including reduced 
income levels [38], time taken off work [39] and OOP expenses related to caring $[17,40]$. In our study, almost $50 \%$ of carers incurred some OOP cost, with an average of $€ 59$ per week across all carers and a maximum of $€ 1020$ per week in the previous 30 days. These costs can include household expenses (for example special food and drink), medicine (for example prescription and over-the-counter medicines), cancer-related items (for example doctor and nurse visits, stoma expenses) and transportation costs [17, 40-42]. Routine additional expenditure of this nature has the potential to accumulate over time and - as suggested by our resultscause a significant financial burden which can, in turn, impinge on carer mental health. Further investigation is warranted of these and their consequences for mental health in different cancer social welfare systems and health systems.

Subjective financial burden and its relationship to carer HRQoL have been relatively under-researched. Previous studies have examined the financial consequences of a diagnosis of cancer and how these can predict patient depression, anxiety and stress $[43,44]$ while previous qualitative research, conducted as part of the wider project from which the current study is drawn, suggests an association between financial burden and emotional burden in colorectal cancer patients [28]. This current study extends the evidence base by further highlighting how carers can be adversely affected in terms of mental health; additional investigation of this important association is warranted in other settings.

While our study confirmed previous findings of high carer esteem in cancer carers (colorectal cancer [45], oral cancer [46], palliative and terminally ill cancer patients [47-49]), it also revealed that higher carer esteem was a predictor of lower mental health. This intriguing result contradicts what might have been expected a priori and suggests some tension between how carers' perceive the experience of caregiving (or how they feel they should perceive or report it) and how it actually impacts upon them emotionally. Further investigation of what might explain this finding is warranted in order to better understand how caregiving impacts emotionally on carers.

Objective factors and carer's physical health

Despite growing recognition of the implications that poor physical functioning has for overall carer well-being, few studies have systematically examined physical HRQoL as a unique construct and how it varies between carers (e.g. [27, 9]). Unsurprisingly, in this study, older carers had significantly lower physical health scores than younger carers. Carers with a comorbid condition also had significantly lower physical $\left(\eta^{2}=.22\right)$, but not mental, health. Taken together, these findings are consistent with recent literature which suggests that older carers are at risk of worsening physical health "doubly burdened" by comorbid conditions and the task of caregiving itself [6]. Indeed, older carers have a $63 \%$ higher mortality rate than the non-carer population of a similar age [50] which suggests an underlying physical risk from caring that cannot be explained by age alone. Given that almost half of the carers in our sample were 61 years or older and $71 \%$ had a comorbid condition, and given the physically intensive nature of the carer tasks involved in caring for someone with colorectal cancer (such as increased household activities (e.g. feeding and dressing) and cancer-specific care (e.g. changing stoma bags and bandages) [17]), such risks may be particularly pertinent in colorectal cancer patient carers.

The significantly lower physical health amongst carers who were spouses of the colorectal cancer patient compared to those who were not was noteworthy $\left(\eta^{2}=.14\right)$. This may be due in part to the complex roles that spouses play in the caregiving process including providing important emotional and practical support [16] as well as the fact that care from spouses, or others who live with the patient, is likely to be more persistent, affording less time for carers to rest from physical duties. Spouses of colorectal cancer patients are also more likely to be involved in certain aspects of care, such as stoma care, than other carers, and this may lead to increased physical strain $[9,14]$.

Interestingly, a decrease in income was associated with higher PCS. The explanation for this is unclear, but we might speculate that carers who took time off work (either of a temporary or long-term nature) and resultantly suffered a fall in income had more time to devote to their caregiving duties, thus lessening the physical burden of care. A similar finding has been reported in relation to the subjective burden experienced by carers of patients with rheumatoid arthritis [51].

\section{Implications}

Some studies suggest cancer carers experience losses in both physical and mental aspects of HRQoL compared to the general population (e.g. [9]), however-as found in this study - these decrements have differing predictors which points to a need to address these aspects of HRQoL separately. Overall, our analysis revealed that risks to carer physical health were associated with carer's subjective burden (including impact on health and schedule) and identifiable sociodemographic and health factors, while risks to carer mental health were only associated with carer subjective factors (including perceived financial burden and esteem). Our findings therefore suggest that sensitivity to variability in carer characteristics, and in particular carer perceived burden of care, is required when assessing carer needs for support over the course of the survivorship continuum. The results from the current study can be utilised, in conjunction with existing data, to formulate theoretically and empirically supported models of HRQoL that integrate both the subjective burden predictors 
and objective predictors of both physical and mental health amongst informal cancer carers.

\section{Strengths and limitations}

An important contribution of this study is its evaluation of the impact carer subjective burden has on carer mental and physical HRQoL. This is the first study to investigate the influence of subjective and objective burden in colorectal carer HRQoL in Ireland and one of only a limited number to examine this area internationally. Our study contains a number of limitations. The survey was cross sectional providing a snapshot at a single point in time, and the career burden, HRQoL effects and the predictors of these may change over the trajectory of the illness and survivorship. In addition the carers included were derived from an initial patient survey and may not be representative of the general population of colorectal cancer patient carers in Ireland. While the response rate was relatively high $(68 \%)$, we cannot exclude the possibility that nonresponders and responders may differ in terms of carer burden or physical or mental health. The primary focus of this study was to provide the first empirical assessment of the impact of perceptions of caregiving on the HRQoL of colorectal cancer patient carers. Future research could expand on this analysis by investigating additional variables that may mediate this relationship.

\section{Conclusion}

We found that subjective burden factors are important predictors of both physical and mental HRQoL amongst colorectal cancer patient carers; however, the domains which predict HRQoL differ for physical and mental health. In addition, while several carer socio-demographic characteristics were associated with physical health, the financial burden of care had a larger impact on carer mental health. Our results demonstrate the need to recognise the distinctive aspects of the HRQoL impact of caring and indicate that strategies to evaluate carer needs must be sensitive both to variability in carer characteristics and perceived carer burden.

\begin{abstract}
Acknowledgments Data collection was funded by the Health Research Board (SA/2004/1). We are grateful to the carers and colorectal cancer survivors who took part in the surveys, the clinicians and nurses who supported the fieldwork and Alan O'Ceilleachair who undertook the patient survey. We also thank the clerical support team at the National Cancer Registry who aided with survey administration and data input.
\end{abstract}

Conflicts of interest Paul Hanly, Rebecca Maguire, Philip Hyland and Linda Sharp declare that they have no conflict of interest.

\section{References}

1. Ferlay J, Steliarova-Foucher E, Lortet-Tieulent J, Rosso S, Coebergh JW, Comber H et al (2013) Cancer incidence and mortality patterns in Europe: estimates for 40 countries in 2012. Eur J Cancer 49:1374 1403

2. National Cancer Registry Ireland (2014) Cancer in Ireland 19942011: annual report of the National Cancer Registry.

3. De Angelis R, Sant M, Coleman MP, Francisci S, Baili P, Pierannunzio D et al (2014) Cancer survival in Europe 1999-2007 by country and age: results of EUROCARE-5 - a population-based study. Lancet Oncol 15:23-34

4. Bray F, Ren JS, Masuyer E, Ferlay J (2013) Global estimates of cancer prevalence for 27 sites in the adult population in 2008. Int J Cancer 132:1133-1145

5. Olson RE (2012) Is cancer care dependant on informal carers? Aust Health Rev 36:254-257

6. Romito F, Goldzweig G, Cormio C, Hagedoorn M, Andersen BL (2013) Informal caregiving for cancer patients. Cancer 119(Suppl 11):2160-2169

7. van Ryn M, Sanders S, Kahn K, van Houtven C, Griffin JM, Martin $M$ et al (2011) Objective burden, resources, and other stressors among informal cancer caregivers: a hidden quality issue? Psychooncology 20:44-52

8. Goren A, Gilloteau I, Lees M, DaCosta DM (2014) Quantifying the burden of informal caregiving for patients with cancer in Europe. Support Care Cancer 22:1637-1646

9. McMullen CK, Schneider J, Altschuler A, Grant M, Hornbrook MC, Liljestrand P et al (2014) Caregivers as healthcare managers: health management activities, needs, and caregiving relationships for colorectal cancer survivors with ostomies. Support Care Cancer 22:24012408

10. Kang J, Shin DW, Choi JE, Sanjo M, Yoon SJ, Kim HK et al (2013) Factors associated with positive consequences of serving as a family caregiver for a terminal cancer patient. Psychooncology 22:564-571

11. Arndt V, Merx H, Stegmaier C, Ziegler H, Brenner H (2004) Quality of life in patients with colorectal cancer 1 year after diagnosis compared with the general population: a population-based study. J Clin Oncol 22:4829-4836

12. Arndt V, Merx H, Stegmaier C, Ziegler H, Brenner H (2006) Restrictions in quality of life in colorectal cancer patients over three years after diagnosis: a population based study. Eur J Cancer 42: 1848-1857

13. Jansen L, Koch L, Brenner H, Arndt V (2010) Quality of life among long-term ( $\geq 5$ years) colorectal cancer survivors - systematic review. Eur J Cancer 46:2879-88

14. Cotrim H, Pereira G (2008) Impact of colorectal cancer on patient and family: implications for care. Eur J Oncol Nurs 12:217-226

15. Ohlsson-Nevo E, Andershed B, Nilsson U, Anderzen-Carlsson A (2012) Life is back to normal and yet not-partners' and patient's experiences of life of the first year after colorectal cancer surgery. $\mathrm{J}$ Clin Nurs 21:555-563

16. Sjovall K, Gunnars B, Olsson H, Thome B (2011) Experiences of living with advanced colorectal cancer from two perspectives - inside and outside. Eur J Oncol Nurs 15:390-397

17. Hanly P, Ceilleachair AO, Skally M, O'Leary E, Kapur K, Fitzpatrick $P$ et al (2013) How much does it cost to care for survivors of colorectal cancer? Caregiver's time, travel and out-of-pocket costs. Support Care Cancer 21:2583-2592

18. Siegel R, DeSantis C, Virgo K, Stein K, Mariotto A, Smith T et al (2012) Cancer treatment and survivorship statistics. CA Cancer J Clin 62:220-241

19. Kim Y, Kashy DA, Spillers RL, Evans TV (2010) Needs assessment of family caregivers of cancer survivors: 3 cohort comparisons. Psychooncology 19:573-582 
20. Stenberg U, Ruland CM, Miaskowski C (2010) Review of the literature on the effects of caring for a patient with cancer. Psychooncology 19:1013-25

21. Taylor C (2008) Supporting the carers of individuals affected by colorectal cancer. Br J Nurs 17:226-230

22. Burridge LH, Barnett AG, Clavarino AM (2009) The impact of perceived stage of cancer on carers' anxiety and depression during the patients' final year of life. Psychooncology 18:615-623

23. Patterson JM, Rapley T, Carding PN, Wilson JA, McColl E (2013) Head and neck cancer and dysphagia; caring for carers. Psychooncology 22:1815-1820

24. Northouse LL, Katapodi MC, Schafenacker AM, Weiss D (2012) The impact of caregiving on the psychological well-being of family caregivers and cancer patients. Semin Oncol Nurs 28:236-245

25. Kim Y, Spillers RL (2010) Quality of life of family caregivers at 2 years after a relative's cancer diagnosis. Psychooncology 19:431440

26. Sjovall K, Attner B, Englund M, Lithman T, Noreen D, Gunnars B et al (2012) Sickness absence among cancer patients in the prediagnostic and the post-diagnostic phases of five common forms of cancer. Support Care Cancer 20:741-747

27. Ross A, Sundaramurthi T, Bevans MA (2013) Labor of love: the influence of cancer caregiving on health behaviors. Cancer Nurs 36: 474-483

28. Ceilleachair AO, Costello L, Finn C, Timmons A, Fitzpatrick P, Kapur K, et al. (2012) Inter-relationships between the economic and emotional consequences of colorectal cancer for patients and their families: a qualitative study. BMC Gastroenterol; 12:62-230X$12-62$.

29. Given CW, Given B, Stommel M, Collins C, King S, Franklin S (1992) The caregiver reaction assessment (CRA) for caregivers to persons with chronic physical and mental impairments. Res Nurs Health 15:271-283

30. Nijboer C, Triemstra M, Tempelaar R, Sanderman R, van den Bos GA (1999) Measuring both negative and positive reactions to giving care to cancer patients: psychometric qualities of the Caregiver Reaction Assessment (CRA). Soc Sci Med 48:1259-1269

31. van den Berg B, Spauwen P (2006) Measurement of informal care: an empirical study into the valid measurement of time spent on informal caregiving. Health Econ 15:447-460

32. Saris-Baglama RN, Dewey CJ, Chisholm GB, Plumb E, King J, Kosinski M, et al. (2007) QualityMetric Health Outcomes ${ }^{\mathrm{TM}}$ Scoring Software 3.0 User's Guide.

33. Blake C, Codd MB, O'Meara YM (2000) The Short Form 36 (SF-36) Health Survey: normative data for the Irish population. Ir J Med Sci 169:195-200

34. Pallant J (2013). SPSS survival manual (5th ed.). McGraw Hill, New York.
35. Cohen JW (1988) Statistical power analysis for the behavioural sciences (2nd ed.). Lawrence Erlbaum Associates, Hillsdale, NJ.

36. Cohen JA (1992) Power primer. Psychol Bull 112:155-159

37. Bevans M, Sternberg EM (2012) Caregiving burden, stress, and health effects among family caregivers of adult cancer patients. JAMA 307:398-403

38. Papastavrou E, Charalambous A, Tsangari H (2009) Exploring the other side of cancer care: the informal caregiver. Eur J Oncol Nurs 13: $128-136$

39. Mehnert A, de Boer A, Feuerstein M (2013) Employment challenges for cancer survivors. Cancer 119(Suppl 11):2151-2159

40. Van Houtven $\mathrm{CH}$, Ramsey SD, Hornbrook MC, Atienza AA, van Ryn M (2010) Economic burden for informal caregivers of lung and colorectal cancer patients. Oncologist 15:883-893

41. Longo CJ, Fitch M, Deber RB, Williams AP (2006) Financial and family burden associated with cancer treatment in Ontario, Canada. Support Care Cancer 14:1077-1085

42. Longo CJ, Deber R, Fitch M, Williams AP, D'Souza D (2007) An examination of cancer patients' monthly 'out-of-pocket' costs in Ontario, Canada. Eur J Cancer Care (Engl) 16:500-507

43. Sharp L, Carsin AE, Timmons A (2013) Associations between cancerrelated financial stress and strain and psychological well-being among individuals living with cancer. Psychooncology 22:745-755

44. Hanratty B, Holland P, Jacoby A, Whitehead M (2007) Financial stress and strain associated with terminal cancer-a review of the evidence. Palliat Med 21:595-607

45. Nijboer C, Triemstra M, Tempelaar R, Mulder M, Sanderman R, van den Bos GA (2000) Patterns of caregiver experiences among partners of cancer patients. Gerontologist 40:738-746

46. Chen SC, Tsai MC, Liu CL, Yu WP, Liao CT, Chang JT (2009) Support needs of patients with oral cancer and burden to their family caregivers. Cancer Nurs 32:473-481

47. Grov EK, Fossa SD, Sorebo O, Dahl AA (2006) Primary caregivers of cancer patients in the palliative phase: a path analysis of variables influencing their burden. Soc Sci Med 63:2429-2439

48. Park CH, Shin DW, Choi JY, Kang J, Baek YJ, Mo HN et al (2012) Determinants of the burden and positivity of family caregivers of terminally ill cancer patients in Korea. Psychooncology 21:282-290

49. Utne I, Miaskowski C, Paul SM, Rustoen T (2013) Association between hope and burden reported by family caregivers of patients with advanced cancer. Support Care Cancer 21:2527-2535

50. Schulz R, Beach SR (1999) Caregiving as a risk factor for mortality: the Caregiver Health Effects Study. JAMA 15:2215-9

51. Brouwer WB, van Exel NJ, van de Berg B, Dinant HJ, Koopmanschap MA, van den Bos GA (2004) Burden of caregiving: evidence of objective burden, subjective burden, and quality of life impacts on informal caregivers of patients with rheumatoid arthritis. Arthritis Rheum 51:570-577 